\title{
ASSÉDIO MORAL COMO ESTRATÉGIA DE GESTÃO NO SERVIÇO PÚBLICO
}

\author{
Moral harassment as a strategy model in public service
}

L'harcèlement moral comme stratégie de gestion au sein du service public

Acoso moral como un estrategia de gestión en la administración pública

\section{Resumo}

Este artigo tem como objetivo desvelar os novos mecanismos de gestão da administração pública contemporânea: a utilização do assédio moral como estratégia de gestão. As mudanças em cena são baseadas na excelência e produtividade, engajam todos os trabalhadores aos valores e interesses da instituição, por meio das normas, metas, sistemas de controle e avaliações dos processos. O estudo, de caráter qualitativo, baseou-se em cinco depoimentos de trabalhadores que tiveram histórias de afastamento no trabalho por transtornos mentais e comportamentais e duas entrevistas com gestores de uma instituição pública. Como procedimento ético, foi apresentado o Termo de Consentimento Livre e Esclarecido/TCLE, e o estudo foi aprovado pelo Comitê de Ética em Pesquisa da universidade. As entrevistas foram interpretadas com base na análise temática. Conclui-se que as novas ferramentas de gestão impõem uma violência simbólica, difusa e gradual, que submete os trabalhadores voluntariamente à nova ordem de gerenciamento por meio de mecanismos de controle e coerçã o caracterizando as sédio moral.

Palavras-chave: Serviço Público; Violência Psicológica; Assédio Moral

\section{Abs tract}

This article aimed to unveil the new management mechanisms of the contemporary public administration, the use of mobbing as a management tool. Changes in scene are based on excellence and productivity, engage all employees to the values and interests of the institution by the rules, goals, control systems and evaluations of processes. The qualitative study, was based on the statements of five workers who had clearance stories at work caused by mental and behavioral disorders and two interviews with managers of an public institution. As an ethical procedure, it was introduced the Informed Consent/TCLE, and the study was approved by the Research Ethics Committee of the University. The interviews were analyzed based on thematic analysis. In conclusion, the new management tools impose a symbolic, diffuse and gradual violence, and voluntarily submitt the workers to a new management order through mechanisms of control and coercion characterizing moral harassment.

Keywords: Public Servant; Psychological Violence; Moral Harassment.

1 vdalcastel@gmail.com 


\begin{abstract}
Résumé
Cet article a pour objectif dévoiler les nouveaux mécanismes de gestion de l'administration publique contemporaine: l'utilisation de l'harcèlement moral comme stratégie de gestion. Les changements actuels reposent sur des critéres d'excellence et de productivité, engagent tous les travailleurs avec les valeurs et les intérêts de l'institution, au travers des normes, des objectifs, des systèmes de contrôle et d'évaluation des processus. L'étude, de type qualitatif, a pour base la réalisation de deux entretiens avec des gestionnaires d'un établissement public, et, d'autre part, de cinq témoignages de travailleurs ayant des antécédents de congé de travail en raison de troubles mentaux et du comportement. En tant que procédure éthique, le Terme de consentement libre et éclairé / TCLE a été présenté, et, par ailleurs, l'étude a été approuvée par le Comité d'éthique de la recherche de l'université. En ce qui concerne l'analyse, les entretiens ont été interprétés sur la base d'une analyse thématique. La conclusion de notre étude est que les nouveaux outils de gestion imposent une violence symbolique, diffuse et progressive, soumettant volontairement les travailleurs au nouvel ordre de gestion par des mécanismes de contrôle et de coercition qui constituent un harcèlement moral.
\end{abstract}

Mots clés: service public; violence psychologique; harcèlement moral.

\title{
Resumen
}

Este artículo tiene como objetivo desvelar los nuevos mecanismos de gestión de la administración pública contemporánea, la utilización del acoso moral como instrumento de gestión. Los cambios en escena son basadas en la excelencia y productividad, involucran todos los trabajadores a los valores e interés de la institución, por intermedio de las normas, metas, sistemas de control y evaluaciones de los procesos. El estudio, de carácter cualitativo, se basó en cinco declaraciones de trabajadores que tuvieron historias de despacho en el trabajo por Trastornos Mentales y Comportamentales y dos entrevistas con gestores de una institución pública. Como procedimiento ético fue presentado el Termo de Consentimiento Libre y Esclarecido/TCLE, y estudio fue aprobado por el Comité de Ética en Pesquisa de la universidad. Como análisis las entrevistas fueron interpretadas con base en el análisis temático. Se concluye que, las nuevas herramientas de gestión imponen una violencia simbólica, difusa y gradual, somete los trabajadores voluntariamente a nueva orden de gerenciamient o or medio de mecanismos de control y coerción caracterizando acoso moral.

Palabras clave: Acoso Moral; Funcionario Público; Violencia Psicológica.

\section{INTRODUÇÃO}

Nas últimas duas décadas o serviço público brasileiro passou a buscar mecanismos de gerenciamento capazes de modificar por meio de tecnologias, regras, normas e procedimentos à qualidade e eficiência dos serviços prestados no atendimento ao usuário/cidadão. Do ponto de vista da gestão, era considerado ineficaz, descomprometido, moroso, sem controle e sem gestão, refém do nepotismo e da corrupção, de outro, gerava a percepção dos servidores públicos como trabalhadores descomprometidos, acomodados, despreocupados, acumuladores de funções e gratificações. Baseado na ideia de ineficiência, o governo criou, em 1990, o Programa Brasileiro de Qualidade e Produtividade - PBQP, que gerou o comitê da administração pública, a origem dos programas de qualidade no serviço público (Brasil, 1995). Com foco nas mudanças dessa realidade brasileira, a partir deste período, o governo federal procurou implantar novas práticas de gestão com integração de lógicas funcionais mais ou menos contraditórias, visando atingir a excelência no desempenho do trabalho público 
brasileiro (Gaulejac, 2007). De acordo com Jorge (2010), o governo brasileiro, seguindo a tendência internacional de tornar o serviço público menos oneroso e mais eficaz, implementou novos modelos gerenciais, originários da iniciativa privada, os quais são descontextualizados do setor público, desconsiderando a finalidade e a importância social desse setor. A partir dessa lógica, passou-se a buscar dispositivos capazes de mensurar os resultados alcançados, baseados no tripé da excelência, avaliação de desempenho e intensificação dos processos.

A nova regulamentação em cena, no setor público, buscou por meio de setores estratégicos, "pôr a funcionar", [grifo nosso] sistemas que impõem alterações importantes nos processos de trabalho dos trabalhadores e que, de forma sutil, aprisionam coletivos de trabalho por meio da disciplina e controle, só que, agora, encobertos por uma violência operada de forma cínica e legitimada por normas e regulamentações nos processos do trabalho. Para essas ferramentas serem operacionalizadas nas instituições, é preciso um conjunto de ações dos gestores, disfarçado por uma normalidade imposta, nas prescrições funcionais e comunicacionais entre os objetivos da organização e as necessidades, buscando maior integração entre as metas e os discursos para alcançá-las.

A busca do alinhamento dos objetivos da instituição pública às necessidades do cidadão trouxe instabilidade ao setor de recursos humanos das instituições, visto que se, de um lado, as novas ferramentas administrativas poderiam garantir maior agilidade no atendimento, de outro, os altos índices de desempenho e produtividade, com diferentes mecanismos de controle e coerção, extrapolam a capacidade física e mental dos servidores. Para Antunes e Praun (2015) "o assédio moral é parte dessa engrenagem" (p.420), ou seja, para os autores o assédio moral passa a estar em consonância com as ferramentas de gestão.

Como consequência a nova estratégia de gestão no serviço público, Navarrete (2001) observa que, o aumento das "patologías laborales" (p. 1553) estão relacionadas a formas singulares de violência extrema e sistemática mais ou menos difusas, indiretas e mais ou menos sutis. A autora denomina o fenômeno da perseguição psicológica e a violência moral no trabalho como uma patologia "socio-laboral" (p.1554) das administrações públicas, que expressa, para ela, uma forma de "perversión degenerativa" (p.1569) das instituições.

$\mathrm{O}$ assédio moral e a violência psicológica praticada no trabalho, como definição, são muito amplas e envolvem aspectos culturais, psicológicos e estruturais das instituiçõ es. Entender as situações vivenciadas no ambiente de trabalho que caracterize a violência psicológica é o caminho para dar visibilidade ao fenômeno, visto que ele é de difícil comprovação. Entretanto, ainda é tratado de forma individualizada, situação que pode mascarar a problemática e tornar-se de difícil compreensão, visto que o trabalhador precisa de fatos 
concretos para comprovar as causas dessa violência no trabalho bem como o consentimento e cumplicidade do grupo para denunciar.

As consequências da violência laboral e do assédio moral na vida pessoal e na profissional, sugerem que os efeitos psicológicos degradantes podem ter características patologizantes e desestruturadoras dos vínculos laborais. Vários pesquisadores brasileiros e de outros países discutem este fenômeno contemporâneo: (Navarrete, 2001; Suárez, 2002; Guimarães \& Rimoli, 2006; Glina, 2010; Seligmann-Silva, 2011; Gaulejac, 2011; Mulder, Pouwelse, Lodewijkx \& Bolman, 2014; Barreto \& Heloani, 2014; Mulder, Pouwelse, Lodewijkx, Bos \& Dam, 2016). Suas definições diferenciam-se, no Brasil, é intitulada de assédio moral, assédio psicológico ou então o termo em inglês, mobbing, e psicoterror, sendo o primeiro mais utilizado, mas tem ao redor do mundo traduções similares para defini-lo como: harcèlement moral (França), molestie psicologiche (Itália), bullying, bossing, harassament (Inglaterra, Austrália e Irlanda), murahachibu (Japão), coacção moral (Portugal) e acoso moral, acoso psicológico ou psicoterrorismo (países hispânicos) (Guimarães \& Rimoli, 2006, p.184).

A partir dessa problemática, o artigo tem como objetivo desvelar, a partir de depoimentos de servidores públicos, vinculados a um órgão do Ministério do Desenvolvime nto Social brasileiro, com histórias de afastamento do trabalho por motivos de transtornos mentais e comportamentais, os meandros institucionais materializados nas normas e procedimentos utilizados para a implantação de um novo modelo de gestão. Tais estratégias gerenciais apresentam-se na forma de métodos de dominação sobre os processos e as pessoas, levando servidores públicos ao afastamento como forma de resistência às pressões, intensificação e exigências de produtividade no trabalho.

\section{MATERIAIS E MÉTODOS}

Este estudo é resultado de uma pesquisa qualitativa, realizada com servidores públicos Técnicos de Seguro Social de um órgão ligado ao Ministério do Desenvolvimento Social brasileiro, responsável por garantir os serviços do programa de seguro público à trabalhadores que contribuem com a previdência social. Por questões éticas a instituição será intitulada de PSSN. 


\section{Participantes}

Participaram da pesquisa cinco servidoras do setor de atendimento de uma agência pública federal da Amazônia que tiveram histórias de afastamento do trabalho por motivos de saúde, com diagnóstico de transtorno mental e comportamental, em conformidade com a Classificação Internacional de Doenças (CID-10). Para seleção dos sujeitos, utilizou-se de um estudo de Silva e Schlindwein (2013) realizado no RH da PSSN, dos afastamentos por agravos mentais na instituição. Neste período 23 servidores tiveram afastamento por licença saúde por transtornos mentais e comportamentais, dentre os CIDs constavam: Transtorno depressivo e de humor (F32 ao F39) e Transtornos neuróticos, transtornos relacionados com o "stress" e transtornos somatoformes (F40 ao F48).

Os trabalhadores (Tabela 1) que aceitaram participar do estudo eram técnicos de seguro social, tinham entre 48 a 56 anos e com mais de vinte anos de serviço. Em complementariedade, realizou-se uma entrevista coletiva com gestores do PSSN, do setor da superintendência regional, a gestora executiva e a assessora administrativa. O tema norteador da entrevista foi o modelo de gestão, em vigência desde 2009 e sua relação com os afastamentos por afeções mentais.

Tabela 1: Servidores que participaram da pesquisa.

\begin{tabular}{|c|c|c|c|}
\hline Participantes & Lotação & Idade & Tipo de afastamento/CID-10 \\
\hline Maria Clara & Agência & 52 & F32 Episódio depressivo \\
\hline Maria Flor & Agência & 50 & $\begin{array}{l}\text { F31.3 Transtorno afetivo bipolar, episódio } \\
\text { atual depressivo leve ou moderado }\end{array}$ \\
\hline Maria Alma & Agência & 48 & F41.1 Ansiedade generalizada \\
\hline Maria Berenice & Agência & 56 & F32 Episódio depressivo \\
\hline Maria Tânia & Agência & 52 & F41.2 Transtorno misto de ansiedade \\
\hline Maria Rita & $\begin{array}{l}\text { Gerência } \\
\text { Executiva }\end{array}$ & 52 & - \\
\hline Maria Zilda & $\begin{array}{l}\text { Gerência } \\
\text { Executiva }\end{array}$ & 50 & - \\
\hline
\end{tabular}

Fonte: Sujeitos participantes da pesquisa de Mattos \& Schlindwein (2015). 


\section{Instrumentos e procedimentos}

Realizou-se entrevistas semiestruturadas, com roteiro predefinido, a técnica permitiu, a partir das entrevistas, compreender o funcionamento da organização do trabalho e os impactos à subjetividade de cada trabalhador, como as vivências conflitantes presentes entre as novas ferramentas de gestão, implementadas a partir de 2009, as quais não tiveram a participação coletiva dos trabalhadores.

Por meio da assinatura prévia do Termo de Consentimento Livre e Esclarecido (TCLE), foram realizadas as entrevistas, nas quais foi possível colher os depoimentos. Para a execução, o projeto foi submetido e aprovado pelo Comitê de Ética em Pesquisa da universidade.

Para a análise das entrevistas, foi utilizada a análise temática (Bardin, 2011), partindose da divisão do texto em unidades de significado, o que possibilita a construção de uma compreensão acerca das vivências no trabalho.

A discussão, apresentada a seguir, está fundamentada nos relatos de servidores públicos que se dispuseram a falar sobre seu trabalho e o sofrimento mental envolvido nas licenças saúde concedidas para reabilitação, além de apresentar a posição dos gestores ao processo de gestão em cena na instituição. Por questões éticas, será utilizado nomes fictícios para todas as participantes.

\section{RESULTADOS E DISCUSSÃO}

\section{Reestruturação produtiva e os discursos organizacionais de eficiência e excelência no serviço público}

A reestruturação dos processos de trabalho com a implementação de novas práticas de gestão, com o objetivo proclamado de atingir a excelência e o desempenho do trabalho, supostamente no sentido de melhorar a qualidade dos serviços prestados, é a nova ferramenta de gestão do setor público brasileiro a partir de 1990.

O governo brasileiro, seguindo a tendência internacional de tornar o serviço público menos oneroso e mais eficaz, vem implementar novos modelos gerenciais, originários da iniciativa privada, os quais são descontextualizados do setor público, sendo desconsiderado a finalidade e a importância social desse setor. Afirma Grateron (1999) a excelência e indicadores de qualidade nos serviços públicos é uma necessidade para as administrações públicas, porque, considerando o cenário atual no qual existem maior exigência do cidadão e menor quantidade 
de recursos, os gestores públicos devem aplicar modelos de gestão empresarial, satisfazendo às necessidades razoáveis dos clientes com o mínimo consumo de recursos.

Nesse intuito de controlar a gestão e melhorar a eficiência nas administrações públicas, foi implantada em alguns órgãos públicos federais e na PSSN a metodologia do Balanced Scorecard (BSC). Com origem nos Estados Unidos, a metodologia rapidamente foi difund ida, sendo hoje aplicada por empresas em todos os continentes (Metzger, Maugeri \& BenedettoMeyer, 2012). Este método é prática gerencial que, inicialmente criada para mensurar o desempenho organizacional, passou a ser utilizada como uma ferramenta para a gestão e implementação de estratégias, gestão de qualidade e gestão do serviço, tendo como base indicadores de avaliação de desempenho. Tal modelo propiciou a criação de um mapa estratégico da instituição estudada, objetivando alcançar as metas definidas no plano de ação institucional.

O mapa estratégico define as estratégias a serem usadas de acordo com os objetivos predefinidos pela organização, os quais estão centrados na produtividade e na eficiência dos serviços prestados pela instituição; todavia, conforme os depoimentos colhidos, a missão prescrita no discurso gerencial da instituição não corresponde às suas práticas cotidianas internas. Segundo os trabalhadores, as mudanças organizacionais fazem ampliar as exigências e pressões sobre os trabalhadores, de modo que quase nunca correspondem a melhorias nas condições de trabalho.

A implantação do novo modelo de gestão trouxe mudanças significativas na estrutura da instituição, na operacionalização das tarefas pelos servidores públicos, no modo de funcionamento (a resolução dos processos passou a ser em "tempo real", [grifo nosso] na prestação de serviços, mas principalmente teve impactos na vida profissional e na pessoal dos trabalhadores, visto que a intensificação do tempo de trabalho foi uma medida gerencial que modificou a rotina de trabalho na instituição, como descrevem Maria Clara, Maria Tânia e Maria Flor:

Esse painel é o tal do BSC, alguémjá explicou para as pessoas que estão trabalhando, o que é isso? Não! Vão empurrando a goela abaixo sem ninguém saber, esse sistema pode ser até que funcione, mas a pessoa tem que fazer parte disso e entender. (Maria Clara).

Há a monitoração do serviço que você está fazendo, se está trabalhando, quantas pessoas eu atendo por minuto e por dia. Pressão por metas, meta individual e institucional, pressão dos colegas, pressão pessoal, você mesma, que sabe que está envolvido num todo, num sistema, ah! porque trabalha em equipe, mas é uma coisa forçada, ah! não quer, tudo bem, vai diminuiro seu salário, mas não vai diminuir só o seu, vai diminuiros dos outros também. (Maria Tânia). 
É a minha matrícula que fica lá apitando e a gerente ligando! Ei, de quem é a matrícula tal? É claro que ela sabe de quem é, mas ela quer o serviço feito né, tem alguém apertando ela. É muito louco! Vão empurrando a goela baixo. (Maria Flor).

Você tem que atingir a meta, todo o tempo você tem que estar ali acompanhando para poder atingir aquela meta se não o seu salário vai despencando, porque existe um plano de cargos e salários através dessa, desse trabalho de desempenho dentro da empresa, então se você cai, então a meta praticamente vai caí, de todo né porque todos estão num barco só. (Maria Tânia).

Um dos grandes conflitos gerados pela implantação desse novo modelo de gestão refere se à jornada de trabalho semanal. Durante algumas décadas, os servidores públicos do PSSN trabalharam sob o regime de $6 \mathrm{~h} /$ dia e adaptaram sua rotina de vida a esse modo de funcionamento. Com o advento da lei n. 11.907/2009, a jornada de trabalho passou a ser de 40 horas semanais, portanto, o serviço exigia $8 \mathrm{~h} /$ dia (Brasil, 2009). Embora essas mudanças fossem observadas na instituição estudada, denunciam as mudanças em cena das últimas décadas nas instituições brasileiras.

Em nome da "nova gestão pública, símbolo de progresso e de modernização", ignorase a capacidade de resistência coletiva dos seus trabalhadores que, protegidos no plano individual, adaptam-se ou não às lógicas gerenciais, funcionais e produtoras de exclusões (Gaulejac, 2011, p. 89). Os gestores, atravessados pela lógica empresarial, buscam por meio das ferramentas de gestão paradoxais legitimar-se como um sistema de dominação-submissão, ou seja, por meio de uma relação afetiva, psíquica aprisiona e se utiliza das contradições para coadunar seus agentes a aceitar coletivamente modalidades de funcionamento que condenam individualmente. Sobre estes mecanismos Maria Berenice e Maria Alma, desabafam:

Você vê que tem que vestir a camisa, não tem outro jeito, quem que vai lutar contra o sistema, a camisa é de força. (Maria Berenice)

Tem um setor que só faz isso, fiscaliza, então essa é uma outra forma de pressão que arrebenta com qualquer pessoa, você não tem liberdade, você não tem autonomia, não tem prerrogativas suas, nenhuma pra fazer o teu serviço, você tem que ser uma máquina, você precisa agir como uma máquina, e aí você se anula, como é que a pessoa pode viver bem se não pode trabalhar com alegria. (Maria Alma).

A gestão por metas tem sido um dos dispositivos utilizados no serviço público que buscam o envolvimento e o engajamento dos servidores aos objetivos institucionais, são coadunados à alinhar-se a excelência em suas operações, imperativo que repercute em todas as relações sociais e hierárquicas dentro e fora dos locais de trabalho (Antunes \& Praun, 2015). A materialização desta lógica se apresenta de forma paradoxal, visto encontrar-se atrelado a um projeto ideológico neoliberal potencializado no ambiente de trabalho. 
Para Franco, Druck e Seligmann-Silva (2010) na atualidade a busca exacerbada de "perfeição e de superioridade", na lógica empresarial (p.237), emerge de uma espécie de “coerção à perfeição humana" (p. 237). Para as autoras em nome da excelência, tem sido corroído as estruturas morais das relações no trabalho e aberto o espaço ao consentimento das ações perversas.

\section{A gestão como sistema de dominação psicológica}

Elkeles e Seligmann-Silva (2010) alertam que as estratégias e táticas utilizadas contemporaneamente nas novas ferramentas de gestão, por meio do exercício de uma dominação totalizante, incidem sobre a unidade biopsíquica (corpo/mente) de cada trabalhador. Para os autores, a prática da gestão por excelência é adoecedora, rompe solidariedades, incrementa o individualismo e afeta a saúde. Esse tipo distorcido de excelência, para os autores, somente atua por meio das políticas referentes à administração de pessoas (área de recursos humanos) e dos direcionamentos assumidos pelas diretrizes da excelência, doutrina dominante que acaba adquirindo conotação de seleção, descarte de todos aqueles que não são os melhores.

No depoimento das servidoras do PSSN, observa-se que a "violência simbólica", apontada por Elkeles e Seligmann-Silva (2010, p.306), é sutil e imposta pela intensificação e controle sobre as atividades a serem executadas. Sobre esses mecanismos Maria Tânia, Maria Flor e Maria Clara descrevem:

É, esse monitoramento todo, essas coisas todas que aconteceramna PSSN, acho que deixa todo mundo ainda, muito nervosos né, com aquela ansiedade, aquela coisa, eo público daqui também não entende que a gente é só servidor, a gente é mandada, cumpre uma legislação que vem lá de cima, não faz as coisas por querer de qualquer jeito, aí eles não entendeme jogam tudo para cima da gente, ás vezes a gente tem que acatar(risos) (Maria Tânia).

As pessoas não percebem porque que estão brigando, porque que estão se comendo, porque que tão morrendo, ninguém nem sabe porque que está acontecendo isso, eles pensam que é o que? O Zezinho que é briguento? O outro? Não é porque fulano é "caxias"? [grifo nosso]. Não é! É esses sistemas que colocaram a gente para trabalhar numa coisa de doido, é para enlouquecer qualquer um mesmo e pronto, porque eles só querem resultado, só isso, só isso, só querem esse resultado. (Maria Flor).

Você tem que cumprir, tem que cumprir, porque se você não cumprir, você vai perder, esse dinheiro já foi te dado, já tá na tua mão, então isso é outra forma de pressão que mexe com o teu psicológico, que mexe com a tua autoestima, você não consegue ser você mesmo, você vira uma máquina, você vira um robô, um escravo do trabalho, porque se você não cumprir, você não fizer, vão te tirar o teu dinheiro, essa é uma outra forma de ameaça, $e$ isso perturba qualquer pessoa, eu tenho que conseguir, eu tenho que conseguir, eu tenho que fazer, eu tenho que fazer, são as metas colocadas pro servidor. (Maria Clara). 
Nas falas das servidoras do PSSN ficam claras as formas utilizadas pela administração no controle e pressão sobre os serviços, o monitoramento em tempo real, a captura de gestos e ações no atendimento e na resolução dos problemas dos usuários/cidadãos, desconsiderando-se os aspectos qualitativos do atendimento.

O sistema de monitoramento e controle do PSSN, chamado de BSC, tem dois dispositivos de controle dos processos de trabalho dos servidores: uma chamada de Sistema de Registro de Frequência/SISREF, responsável por controlar a frequência dos servidores, como: assiduidade, pontualidade, tempo de intervalo e eventuais saídas não programadas. Se haviam horas trabalhadas, além do horário, são depositadas em um banco de horas que deverá ser utilizado no mês vigente, não sendo cumulativas para outro período. Outro sistema, constituise de um painel de controle, localizado nas salas da Gerência Executiva da regional e nacional, como nas unidades da PSSN. A gestora ao verificar, por exemplo, que em determinada unidade tem uma pessoa esperando na fila há uma hora para ser atendida, o indicador Tempo Médio de Espera/TME é acionado automaticamente e uma luz vermelha começa a piscar no monitor (do servidor e nas gerências), indicando que o atendimento não foi realizado no tempo estabelecido. Há uma seção destinada para o acompanhamento do funcionamento da unidade pelo painel, que no caso, é responsável por verificar porque o atendimento ainda não foi realizado. Por vezes, esta verificação parte de Brasilia que cobra o gestor regional, que por sua vez, cobra o servidor no cumprimento da meta estabelecida no plano diretor (Mattos \& Schlindwein, 2015).

É porque eles lá sabem tudo o que você está fazendo aqui né, monitoração do serviço que você está, se você está trabalhando, se você está atendendo bem, se você está atendendo quantas pessoas por dia, quantos minutos você atende a pessoa, de tudo eles veem. (Maria Tânia).

Você acha que está ali, mas não estão te vigiando, estão te vigiando, mas não fisicamente, pelo computador, estão vendo tua senha, o que tu está trabalhando, o que tu está deixando de fazer, o que tu não está, porque tu não chamou $x$, tá entendendo? Era pra ter chamado x e não chamou por quê?? (Maria Alma).

As metas e objetivos estabelecidas no plano estratégicos são cobradas por meio de emails e mensagens no próprio sistema de cada um, e o não cumprimento dos planos de ação estabelecidas possui consequências institucionais e individuais, em nível de unidade e de servidor. Sendo que a gratificação por desempenho, representa a parcela mais significativa dos rendimentos dos servidores. As metas são compartilhadas por todos os servidores da instituição, no entanto há metas individuais correspondentes ao setor em que o servidor atua, e que o não cumprimento destas implica em reduções significativas nos rendimentos de todas as equipes (Mattos, 2013). 
A nova lógica perpetua-se sustentada por uma doutrina, em nome da excelência, típica de uma ideologia gerencialista, que demanda atitudes contraditórias, como a de ser (individualmente) vencedor e (coletivamente) colaborador, ou de produzir muito, mas com qualidade e com poucos recursos (Gaulejac, 2011), e que leva à instalação de uma cultura propícia à violência, imposta, mas marcada pela sutileza, de modo a disfarçar a dominação (Franco, Druck \& Seligmann-Silva, 2010, p. 231). A inserção dos paradigmas da eficiência acontece com a imposição do medo de discordar das normas, já que, para a realização das atividades, há exigências que são incompatíveis entre si; mas torna-se absolutamente necessário o indivíduo submeter-se às mudanças ou viver o dilema de ser excluído do coletivo de trabalho.

Nesse processo, cada trabalhador tenta ultrapassar o próprio limite subjetivo para dar conta das exigências. Porém sabe-se que muitas vezes aquele só identifica que o limite foi ultrapassado quando algo incômodo o aflige ou quando uma doença o acomete.

A condição de ter de ultrapassar suas próprias limitações passa a ser norma para a execução das tarefas. Um exemplo disso é a ameaça de reduzir as gratificações financeiras, descritas por Maria Clara, e não apenas a do trabalhador "infringente", [grifo nosso] mas de toda a equipe, com base nos escores de produtividade. Nesse sistema, as compensações financeiras passam a regular as relações de trabalho, visto que a responsabilidade pelo fracasso ou sucesso da instituição está na possibilidade de ir além dos limites humanos de cada trabalhador.

Quando o sujeito é forçado a obedecer, mesmo não aceitando as exigências que não sejam passíveis de execução de forma satisfatória, a elas se submete por causa dos aspectos punitivos da redução financeira e desaprovação das hierarquias e dos colegas. Esse é um dos mecanismos de coerção do modelo gerencial inconciliável: subordinação/dominação/punição/gratificação financeira. E, quando o servidor público não consegue se desvencilhar da condição de dominado, ocorre a dupla coação contraditória: ele é instado a ser autônomo e criativo, mas a gestão é estruturalmente coercitiva e quer levar o sujeito a submeter-se, voluntariamente e com toda a liberdade, às amarras do sistema. Eis a manipulação do inconsciente e tentativa da gestão de colocar o ideal de ego organizacional, no lugar de seu ideal de ego, de modo a produzir uma espécie de submissão ao mesmo tempo involuntária (inconsciente) e voluntária (consciente), uma adesão, em detrimento da saúde e à custa do empobrecimento da identidade (Pagès, Bonetti, Gaulesiac \& Descendre, 1987).

Nos depoimentos das gestoras, abaixo, é possível identificar a loucura racional dos novos modelos de gestão, baseados no gerencialismo, na intensificação do tempo e do ritmo, mostrando-se perversos e autoritários. 
A regra de negócio da instituição ela está aqui, então na realidade ela se sustenta em que, todos os servidores da casa uns numa melhor qualidade, outros não, internalize esses processos de trabalho. Eu gostava chamar de regras do robô (grifo do autor) (a gestora refere-se à instrução normativa da PSSN). O servidor público ele é um robô, ele é um robô, ele só pode fazer aquilo que está escrito, ele não pode interpretar. $O$ que é demandado na questão administrativa, por exemplo, compromisso de meta, muitos acham que é um assédio moral e não é bem isso. São políticas institucionais, diferenciam completamente de assédio moral. Alguns servidores acreditam que muitas vezes essas ferramentas de gestão, ferramentas de acompanhamento, de monitoramento, essas cobranças sistemáticas do efeito cascata, acabam em alguns momentos se confundindo comassédio moral. (Maria Zilda).

Nós somos monitorados vinte e quatro horas aqui dentro, aqui a minha senha aqui se estiver trabalhando, se eu estiver atendendo tem alguém me monitorando em qualquer lugardo Brasil não é só em Brasília não, eu entro em uma tal de sala aqui, na sala que eu vejo quem trabalha quem não trabalha, e nós temos metas para cumprir, então esta meta ela nos sobrecarrega. Ultrapassou o limite, na verdade. Eu costumo dizer, em algumas reuniões de gestão que eu vou com meus pares(gestores), é o seguinte, que a gente tem que entender que já entrou na fase do caótico e que a verdade é bem essa. Vocês já exigiram a máxima capacidade operacional, de praticamente cem por cento de servidores. Daí você só consegue ir pra baixo, você vai pra baixo ou foi porque o servidor desencantou ou porque ele não aguenta mais, ele próprio ele recua, ou o servidor começa a adoecer, e alguns que poderiam dar mais alguns anos de trabalho, que ele já está na fase da aposentadoria, ele não pensa duas vezes, ele sai mesmo. Mesmo que ele perca cinquenta por cento do valor daquela gratificação. Então é isso que nós estamos agora o governo federal, por outro lado, não autoriza contratarmais pessoas. (Maria Rita).

As gestoras, cientes dos paradoxos organizacionais, reconhecem que a "racionalidade instrumental é soberana" (Gualejac, 2011, p.91), o modelo de gestão vigente utiliza-se de todos os recursos operatórios dos servidores públicos às mudanças dos processos na instituição, e, para os administradores dessa nova ordem, as resistências precisam ser superadas, é preciso saber como eliminar os obstáculos às inovações necessárias.

Seguir as "regras do robô" (Maria Zilda) significa adequar-se às normas impostas nas instruções normativas do PSSN, é condição para que o sistema funcione. Nesse processo, as pressões, o controle, as avaliações de desempenho seguem selecionando, por meio de relações assimétricas e autoritárias, os melhores e os difíceis de conviver. A submissão a essas relações antagônicas abre um campo para a utilização do assédio como instrumento de gestão.

O fato é que o assédio no trabalho pode tratar-se de um meio estratégico que os gestores encontram de forçar o servidor público a sujeitar-se às mudanças, já que não podem demitir, no serviço público, o gestor não tem 'liberdade' de concretizar seu desejo, mas pode intervir na equipe, forçando o trabalhador a coadunar ou encontrar outra solução, utiliza-se para isto, a estrutura hierárquica para perseguir, humilhar e promover um terror psicológico, forçando o funcionário a buscar uma maneira de pedir mudança de setor, o afastamento por adoecimento ou, no limite, a demissão. 
Esses procedimentos são descritos por Hirigoyen (2015) como perversos, trata-se de colocar cada vez mais pressão até que as pessoas não aguentem. Mas a autora lembra que nem toda a pressão no trabalho é um assédio moral, mas pode desencadear condutas antiéticas nas relações de trabalho.

As políticas institucionais da PSSN asseguram por meio das ferramentas de gestão condição Sine qua non administrar e organizar o trabalho. Segundo Barreto e Heloani (2014, p. 56), essa é a nova lógica do gerenciamento, nos dias atuais: sobrecarregar de trabalho e pressionar moralmente todos os trabalhadores para coadunar com a nova ordem. Para os autores, estão aí as raízes do assédio ou violência laboral, aos gestores é atribuída a insígnia de extrair “[...] a capacidade máxima operacional” (Maria Rita) dos trabalhadores.

Fica evidente, no modelo gerencial das gestoras do PSSN, a exclusão do sofrimento humano, absorve-se a atividade pessoal do trabalhador e ignora-se a variabilidade dos processos fisiológicos e mentais. A gestora sinaliza que a capacidade de se adequar aos processos vem mostrando resistências, muitos vêm adoecendo, na expressão de Maria Flor, "se você adoecer você quebrou". Navarrete (2001) adverte para os riscos do desenvolvimento de "patologias laborales" (p. 1553), advindas da organização do trabalho e da gestão de pessoas nas administrações públicas, e a violência moral no trabalho é um campo para a emersão e desenvolvimento de gravíssimas patologias que podem levar o servidor à deterioração da sua dimensão psicossocial. Maria Flor e Maria Clara afirmam que o assédio e a violência laboral são os pilares das relações sociais na execução dos novos processos de trabalho.

As pessoas não entram com o pedido de doença ocupacional? Existe um estigma sobre isso, se a pessoa apresenta uma CAT (Comunicação de Acidente de Trabalho), ela é na hora marginalizada, ela não quer trabalhar, e aí ninguém quer. [...] um monte de colega vivencia de modo diferente as coisas, mas vivencia, mas não fala porque tem medo! Medo de ser chamado de doido, de louco, quando não é, é melhor você dizer logo estou pifando, tem uma coisa errada acontecendo comigo. Eu via as coisas, me doía demais ver como era na agência as pessoas se matarem de trabalhar, você via as pessoas chegando na agência, lindo, bonito, pele bonita, magro, esbelto, aí com dois anos você via a pessoa sair um bagaço, gordo, a pele uma coisa, o cabelo esfiapado, eu digo gente isso aqui é um lugarde adoecer. Qualquerafastamento aqui você é visto, se torna marginal, aqui você não pode adoecer, porque se você adoecer você quebrou! Você não pode quebrar aqui, se você quebrou aqui, você está com defeito, [...] na agência você não pode quebrar, porque na agência você tem que está $100 \%$, aqui você ainda pode quebrar, porque aqui já é o lugar para os quebrados, aqui já está cheio de gente quebrada. (Maria Flor).

Como é que uma pessoa saudável, uma pessoa que trabalha, uma pessoa que faz as suas atividades, é, de forma a contento, como é que de repente a pessoa está doente? Aí isso foi um choque, então essa parte eu não aceitei bem, eu não aceitei, por quê?? Por que todo mundo trabalha, eu ajudo o governo, coisa que eu produzo, que eu faço parte do sistema, por que eu tenho que ficar doida dentro do sistema? Aí, aí eu fiquei perturbada, porque eu tinha que procurar um psiquiatra, isso me incomoda muito, então não aceitei, não aceitei. O sistema de trabalho que está de um jeito, ele está 
fabricado para você não olhar nem para lá nem para cá, só para você produzir, produzir, produzir, produzir! Por que eu não estou conseguindo enxergar as pessoas, eu olho e não vejo o rosto, não está certo isso, foi o início do processo de adoecimento, eu não dava conta mais, aí o que que eu fiz? Eu tirei a cara das pessoas! Era muito mais fácil para mim. (Maria Clara).

Os depoimentos acima demonstram como se sentem aqueles que foram adoecendo no processo em cena. Os servidores públicos passam a sofrer a violência laboral de modo mais explícito e transparente, os que adoeceram já não condizem com os padrões de excelência e, portanto, não serve mais para o lugar dos melhores. A partir desse momento, começa o processo de isolamento, não apenas pelas ações e atitudes das chefias, mas, também, pela omissão dos colegas que, por medo ou vergonha, acabam reproduzindo o clima de terror instalado. É o que Barreto (2003) denomina de "pacto da tolerância e do silêncio no coletivo" (p.32).

\section{CONSIDERAÇÕES FINAIS}

Observa-se a partir dos depoimentos a introdução da nova dinâmica de gestionarização, desde 2009, na PSSN. As novas tecnologias modificaram a resolução dos processos de trabalho, como também criaram ferramentas de avaliação de desempenho individual e coletiva de mensuração e controle do tempo no atendimento prestado ao cliente/cidadão. Essas práticas operam uma violência difusa e, por meio das pressões, a cooptação do potencial cognitivo de cada um, criam uma espécie de "alienação consentida" (Metzger, et al, 2012, p.226). Seus efeitos residem no exercício de uma violência simbólica pela qual os indivíduos e coletivos são cada vez mais incapazes de pensar seu trabalho para além das categorias de gestão.

As novas tecnologias de gestão na instituição, baseadas no sistema BSC, são marcadas pelas ideias de excelência e efetividade no atendimento e qualidade total e utilizam-se de ferramentas de controle, metas e avaliações de desempenho com vistas à produtividade. Essa lógica passa a mascarar a dominação e precarização das relações de trabalho, com vistas a melhorar e tornar mais eficientes os serviços prestados. Inserir o serviço público brasileiro nessa lógica capitalista, alienante e exploratória é sem dúvida uma violência laboral que afeta os processos psicológicos, o corpo fisico e as relações sociais.

Os dispositivos de gestão do BSC caracterizam-se por uma violência simbólica e perversa na administração pública que impossibilita indivíduos e coletivos de trabalho, de pensar seu trabalho para além das metas e das normas prescritas nos processos organizacio nais de trabalho. O modelo de gestão do PSSN conduz à instalação de uma cultura propícia à 
violência e ao assédio moral no trabalho, até ao ponto em que os trabalhadores não aguentem e adoeçam.

Conclui-se que o assédio moral é uma forma perversa de gestão, ou uma maneira perversa de conduzir as relações sociais no trabalho, tudo indica que as modificações impetradas no serviço público no Brasil, conjuntamente com sua organização histórica, transformaram o assédio moral em uma estratégia de escolha para a gestão, chefes que não tem a estrutura organizacional ou o preparo para chefiar, gerentes que não gerenciam, transformam o assédio moral em uma obrigação do gestor em busca da eficiência.

\section{REFERÊNCIAS}

Antunes, R., Praun, L. (2015). A sociedade dos adoecidos no trabalho. Serviço Social e Sociedade, 123, 407-427. Recuperado de: http//dx.doi.org/10.1590/0101-6628.030.

Bardin, L. (2011). Análise de conteúdo (ed. 70). São Paulo.

Barreto, M. (2003). Violência, saúde e trabalho: uma jornada de humilhações. São Paulo: Educ.

Barreto, M., \& Heloani, R. (2014). O assédio moral como instrumento de gerenciamento. In Á. R. C., Merlo; C. G. Bottega, \& K. V. Perez (Orgs.), Atenção à saúde mental no trabalhador: Sofrimento e transtornos relacionados ao trabalho (Cap. 3, pp. 52-74). Porto Alegre: Evangraf.

Brasil. (1995). Presidência da República. Câmara da Reforma do Estado. Plano diretor da reforma do aparelho do estado. Brasília, DF: Recuperado de: http:/www.bresserpereira.org.br/documents/mare/planodiretor/planodiretor.pdf.

Brasil. (2009). Presidência da República. Dispõe sobre a reestruturação da composição remuneratória das Carreiras de Oficial de Chancelaria e de Assistente de Chancelaria, DF: Recuperado de: http://www.planalto.gov.br/ccivil_03/_ato20072010/2009/lei/11 1907.htm.

Elkeles, T., \& Seligmann-Silva, E. (2010). Aspectos do trabalho relacionados à saúde mental: assédio moral e violência psicológica. In M. R. Glina, \& L. E. Rocha (Orgs.), Saúde mental no trabalho: da teoria à prática (Cap. 2, pp. 302-334). São Paulo: Roca.

Franco, T., Druck, G., \& Seligmann-Silva, E. (2010). As novas relações de trabalho, o desgaste mental do trabalhador e os transtornos mentais no trabalho precarizado. Revista Brasileira de Saúde Ocupacional, 35(122), 229-248. Recuperado de: http://dx.doi.org/10.1590/S0303-76572010000200006.

Gaulejac, V. (2011). A NGP: A Nova Gestão Paradoxal. In P. F. Bendassolini, \& A. P. Soboll (Orgs.), Clínicas do Trabalho: novas perspectivas para compreensão do trabalho na atualidade (Cap. 5, pp. 84-98). São Paulo: Atlas. 
Gaulejac, V. de. (2007). Gestão como doença social: ideologia, poder gerencialista e fragmentação social. São Paulo: Idéias e Letras.

Glina, D. M. R. (2010). Assédio moral no trabalho. In D. M. R. Glina, \& L. E. Rocha (Orgs.), Saúde mental no trabalho: da teoria à prática (Cap. 22, pp. 427-435). São Paulo: Roca.

Grateron, I. R. G. (1999). Auditoria de gestão: utilização de indicadores de gestão no setor público. Caderno de Estudos, (21), 01-18. Recuperado de: http://dx.doi.org/10.1590/S1413-92511999000200002.

Guimarães, L. A. M., \& Rimoli, A. O. (2006). 'Mobbing”' (Assédio Psicológico) no Trabalho: Uma Síndrome Psicossocial Multidimensional. Psicologia: Teoria e Pesquisa, 22(2), 183192. Recuperado de: http//dx.doi.org/10.1590/S0102-37722006000200008.

Hirigoyen, M. F. (2015). Mal-estar no trabalho: redefinindo o assédio moral. Rio de Janeiro: Bertrand Brasil.

Jorge, L. A. F. (2010). O novo modelo de gestão do INSS e os resultados na gerência executiva em Porto Alegre. (Trabalho de conclusão de curso de especialização). Programa de PósGraduação em Administração, Universidade Federal do Rio Grande do Sul, Porto Alegre, RS, Brasil. Recuperado de: https:/www.lume.ufrgs.br/bitstream/handle/10183/40349/000815589.pdf? sequence=1.

Mattos, C. B. M., \& Schlindwein, V. L.Dal C. (2015). "Excelência e produtividade": novos imperativos de gestão no serviço público. Psicologia \& Sociedade, Belo Horizonte - MG, 27(2), 322-331.

Mattos, C. B. M. (2013). "vestir a camisa de força”: adoecimento psíquico em uma instituição pública na Amazônia. (Dissertação de Mestrado). Programa de Pós-Graduação em Psicologia, Universidade Federal de Rondônia, Porto Velho, RO, Brasil. Recuperado de: http://www.ri.unir.br/jspui/bitstream/123456789/1298/1/Cristiane\%20B.\%20M.\%20Matt os_Vestir\%20a\%20camisa\%20de\%20for\%C3\% A7a.pdf.

Metzger, J-L., Maugeri, S., \& Benedetto-Meyer, M. (2012). Predomínio da gestão e violência simbólica. Revista Brasileira de Saúde Ocupacional, 37(126), 225-242. Recuperado de: http://dx.doi.org/10.1590/S0303-76572012000200005.

Mulder, M.; Pouwelse, M.; Lodewijkx, H., \& Bolman, C. (2014). Workplace mobbing and bystanders' helping behavior towards victimis: The role of gender, perceived responsibility and anticipated stigma by association. International Journal of Psychology, 49(4), 304312. Recuperado de: https:/onlinelibrary.wiley.com/doi/epdf/10.1002/ijop.12018?purchase_site_license=LIC ENSE_DENIED\&show_checkout=1\&r3_referer=wol\&purchase_referrer=onlinelibrary. wiley.com\&tracking_action=preview_click\&.

Mulder, R. Pouwelse, M. Lodewijkx, H. Bos, A., \& Dam, K. (2016). Predictors of Antisocial and Prosocial Behaviour of Bystanders in Workplace Mobbing. In Journal of Community \& Applied Social Psychology, 26(3), 207-220. Recuperado de: https:/doi.org/10.1002/casp.2244.

Navarrete, C. M. (2001). Una nueva patologia de gestión em el empleo público: el acoso institucional (mobbing). La Ley: Revista jurídica española de doctrina, jurisprudencia y 
bibliografía,

7,

1553-1571.

Recuperado

de:

http://www. mobbing.nu/unanue vapatologia.htm.

Pagès, M., Bonetti, M., Gaulesiac, M., \& Descendre, T. (1987). O poder das organizações. São Paulo: Atlas.

Seligmann-Silva, E. (2011). Trabalho e desgaste mental: o direito de ser dono de si mesmo. São Paulo: Cortez.

Silva, T. S., \& Schlindwein, V. L. dalC. (2013) Adoecendo no serviço público: afastamentos por transtornos mentais no Instituto Nacional de Seguridade Socia/INSS de Rondônia [Resumo]. In Programa Institucional de Bolsas e Trabalho Voluntário de Iniciação Científica - PIBIC (Org.), resumos de comunicações científicas, XXII Seminário Final do Programa Institucional de Bolsas e Trabalho Voluntário de Iniciação Científica PIBIC/UNIR/CNPq (p.30). Recuperado de: http://www.pibic.unir.br/uploads/78787878/arquivos/827_anais_do_pibic_2012_2013_ 26_nov_2013_a5a_1_atual_1591911020.pdf.

Suárez, O. A. (2002). La violencia psicológica en el lugar de trabajo en el marco de la unión europea. Lan Harremanak: Revista de Relaciones laborales, II(7), 279-296. Recuperado de: http./www.ehu.eus/ojs/index.php/Lan_Harremanak/article/view/5834/5510. 